\title{
Elective Repair of Adult Abdominal Wall Hernia: A Nigerian Tertiary Hospital Experience
}

\author{
Emeka Ray-Offor and Chidi Joshua Okeke
}

\section{ABSTRACT}

\begin{abstract}
Background: Hernia repair is one of the most common procedures performed by general surgeons, mostly in an elective setting. The true incidence/prevalence of hernias in Nigeria is unknown, however, suture (tissue) repair is predominantly reported.
\end{abstract}

Aims: To study the distribution of adult abdominal wall hernia and the surgical and anaesthetic techniques for elective repair in a Nigerian tertiary hospital.

Methods: A retrospective cross-sectional study of surgical patients undergoing elective abdominal wall hernia repair in University of Port Harcourt Teaching Hospital Nigeria from January 2009 to December 2014. Data extracted from the theatre records were patients' demographic, type of hernia, repair technique, anaesthesia, operating time, and cadre of performing surgeon. Statistical analysis was performed using SPSS version 20.

Results: A total of $\mathbf{4 0 0}$ adult patients had elective repair of abdominal wall hernias during study period. The age range was from 17- 85 years (mean $39.3 \pm 6.0$ ) and $M: F$ ratio of $1.9: 1$. There were $287(70.9 \%)$ inguinal, 43(10.6\%) incisional and $36(8.9 \%)$ epigastric hernias. Mesh repair was recorded in $11(2.7 \%)$ cases with laparoscopic technique in 2 cases. Subarachnoid block was the choice anaesthesia in $365(85.4 \%)$ cases. The least mean operating time (38.6 mins) recorded was in repair of femoral hernia and longest (105.3mins) with incisional hernia repair.

Conclusions: Suture repair is the predominant repair technique. Routine hernioplasty and laparoscopic hernia repair need to be encouraged.

Keywords: Abdominal wall, hernia, repair.

\section{INTRODUCTION}

Generally, a hernia is an abnormal protrusion of a viscus through a defect in the wall of cavity encompassing the viscus. Ventral hernias are defects of the fascia in the anterior abdominal wall with or without protrusion of viscus [1]. The hernias from the abdominal wall include the more common groin hernias, umbilical/paraumbilical hernias, epigastric, and incisional hernias. The less common ones include Spigelian, lumbar, and traumatic hernias. They may be primary without precipitating factors or acquired through conditions that weaken the anterior abdominal wall. Surgical treatment of anterior abdominal wall hernia is one of the most common procedures performed by general surgeons, mostly in an elective setting. It is estimated that worldwide, 20 million patients with hernias are operated on every year, with approximately $30 \%$ as ventral hernias [2]. The repair rate ranges from 10 per 100000 population in the United Kingdom to 28 per 100000 in the United States [3]. In Nigeria, the true incidence/prevalence of abdominal wall

hernia is unknown. longer learning curve.
Published Online: January 19*, 2021

ISSN: 2593-8339

DOI: $10.24018 /$ ejmed.2021.3.1.668

\section{Emeka Ray-Offor*}

Department of Surgery, University of Port Harcourt Teaching Hospital, Nigeria. (e-mail: erayoffor@gmail.com)

\section{Chidi Joshua Okeke}

Department of Surgery, University of Port Harcourt Teaching Hospital, Nigeria. (e-mail: chidiokeke75@gmail.com)

*Corresponding Author

Despite some consensus among general surgeons in treatment of some abdominal wall hernias, there is still significant difference in the methods, techniques and routes that are used in various centres across the globe, and at different situations [4]. More so complications and outcome of treatment have varied among the various methods or techniques of repair in subjects with similar demographic and socioeconomic features [5]. Broadly, hernia repairs are performed by open (tissue or mesh) and minimally invasive repair techniques. There are recent significant advances in surgical technique, types of mesh, fixation devices, imaging techniques and the understanding of abdominal wall biomechanics. Laparoscopic repair of incisional and ventral hernias is superior to open mesh repair in terms of significantly less blood loss, fewer complications, shorter hospital stay, and excellent cosmetic outcome [6], [7]. There are however longer operative times, increased cost and

An accurate database for abdominal wall hernia may 
encourage the need to institutionalize the management of hernias as a sub-specialty, for better treatment outcome with reduced complications. In such arrangement, skills in new models of treatment like laparoscopic hernia repairs for both the trainers and the trainees will be improved. The epidemiology of abdominal wall hernias is a firm basis for other studies or research in these conditions at local, regional, or national level. Such studies highlight the resources needed in terms of cost and clinic/theatre spaces, that are spent on these procedures and the need for best practices. This will re-awaken health care providers to the volume and spread of these quite common general surgery procedures.

This study aims to document the distribution of abdominal wall hernias including the surgical and anaesthetic techniques for the elective repair, in a Nigerian tertiary hospital in Niger delta, Nigeria.

\section{METHODS}

\section{A. Study Design /Setting}

A retrospective cross-sectional observational study of consecutive patients undergoing elective abdominal wall hernia repair by two general surgery units from January 2009 to December 2013 (5 years). The study setting was University of Port Harcourt Teaching Hospital Port Harcourt, a 720-bed tertiary health facility in Rivers State, Niger delta region of Nigeria.

\section{B. Inclusion and Exclusion Criteria}

There was inclusion of all consecutive cases of adult elective ventral hernia repair cases. Exclusion criteria included patients aged below 17 years and emergency surgeries for abdominal wall hernias during the study period.

\section{Data Collection}

Data extracted from hospital theatre records included demographics, period, type of ventral hernia, repair method, choice of anaesthesia, operating time, and cadre of surgeon.

\section{Statistical Analysis}

The data was analysed using Statistical Package for Social Sciences, IBM SPSS for Windows, and Version 20.0
(Armonk, NY: IBM Corp). The continuous variables are presented as mean \pm standard deviation (SD) and categorical variables as simple percentages.

\section{RESULTS}

A total of 400 patients had elective repair of abdominal wall hernias thus included in the study. The age range was from 17- 85 years (mean $39.3 \pm 6.0$ years). There were 262 males and 138 females; a male to female ratio of 1.9:1 (Table I). A male predominance of 6.7:1 for inguinal hernia was recorded. However, a female predominance was recorded for all other hernia types (Fig. 1).

\begin{tabular}{cccc}
\multicolumn{3}{c}{ TABLE I: DEMOGRAPHICS OF HERNIA PATIENTS DURING STUDY YEARS } \\
\hline $\begin{array}{c}\text { Age group } \\
\text { (years) }\end{array}$ & Male & Female & Total \\
\hline$<20$ & 11 & 1 & 12 \\
$20-29$ & 73 & 23 & 96 \\
$30-39$ & 54 & 46 & 100 \\
$40-49$ & 57 & 26 & 83 \\
$50-59$ & 32 & 23 & 55 \\
$60-69$ & 23 & 10 & 33 \\
$\geq 70$ & 12 & 9 & 21 \\
Total & 262 & 138 & 400 \\
\hline
\end{tabular}

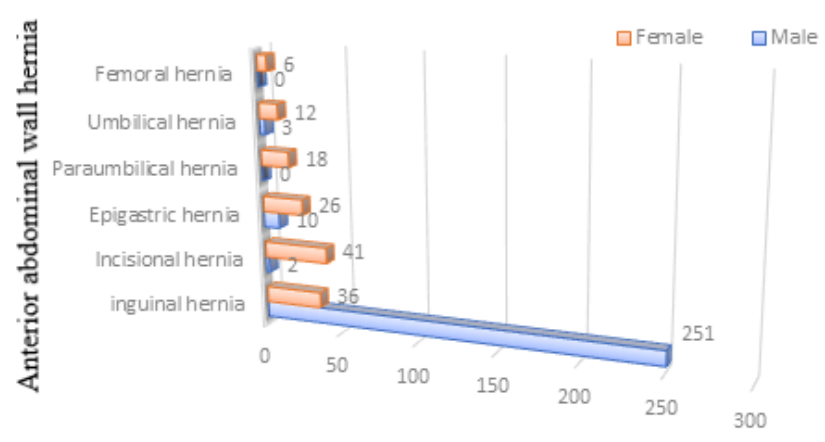

Frequency

Fig. 1. Sex distribution of abdominal wall hernia cases.

In all, 405 hernias were repaired with multiple sites (1 groin and 1 ventral hernia) in 5 out of the 400 patients. The distribution of hernias in decreasing order of frequency was inguinal-287(70.9\%), incisional- 43(10.6\%), epigastric$36(8.9 \%)$, paraumbilical-18(4.4\%), umbilical-15(3.7\%) and femoral-6(1.5\%) (Table II). No spigelian or lumbar hernia was recorded.

TABLE II: AGE DISTRIBUTION OF DIFFERENT TYPES OF ABDOMINAL HERNIA IN STUDY POPULATION

\begin{tabular}{|c|c|c|c|c|c|c|}
\hline Age & Inguinal & Incisional & Epigastric & Umbilical/Paraumbilical & Femoral & Total \\
\hline$<20$ & 12 & 0 & 0 & 1 & 0 & 13 \\
\hline $20-29$ & 76 & 7 & 4 & 8 & 2 & 97 \\
\hline $30-39$ & 56 & 15 & 11 & 17 & 1 & 100 \\
\hline $40-49$ & 62 & 12 & 6 & 3 & 0 & 83 \\
\hline $50-59$ & 40 & 6 & 8 & 1 & 1 & 56 \\
\hline $60-69$ & 25 & 2 & 3 & 3 & 1 & 34 \\
\hline$\geq 70$ & 16 & 1 & 4 & 0 & 1 & 22 \\
\hline Total & 287 & 43 & 36 & 33 & 6 & 405 \\
\hline
\end{tabular}

During this five-year period, an average of 59.6 elective adult inguinal hernia repairs per annum were performed. The trend of groin hernia repair over the years of study is shown in Fig. 2. No femoral hernia was recorded in the latter years of study. The undulating trend of ventral hernia repairs during the study period is shown in Fig. 3.

Suture repair for abdominal wall hernias was predominant in $390(97.5 \%)$ patients and mesh repair recorded in only $11(2.7 \%)$ surgeries. Sub-arachnoid block was the anaesthetic choice in $346(85.4 \%)$ patients. A sole case each of laparoscopic ventral hernia repair and a laparoscopic transabdominal preperitoneal inguinal hernia repair under general anaesthesia were recorded (Table III).

Trainee surgeons performed most surgeries- Senior 
registrars 236(59.0\%) and Registrars 59(14.8\%). Femoral hernias had the least mean operating time of $38.6 \mathrm{mins}$ while incisional hernia repair had the longest - 105.3mins (Table IV).

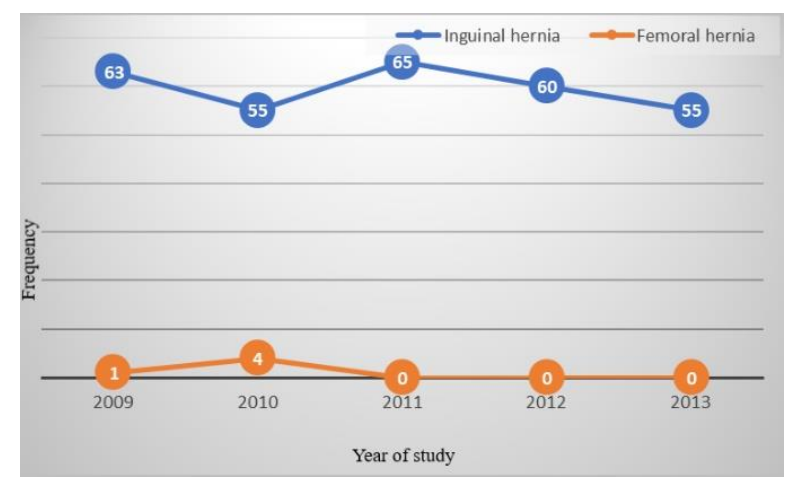

Fig. 2. Trend in groin hernias from University Teaching Hospital Port Harcourt (2009-2013)

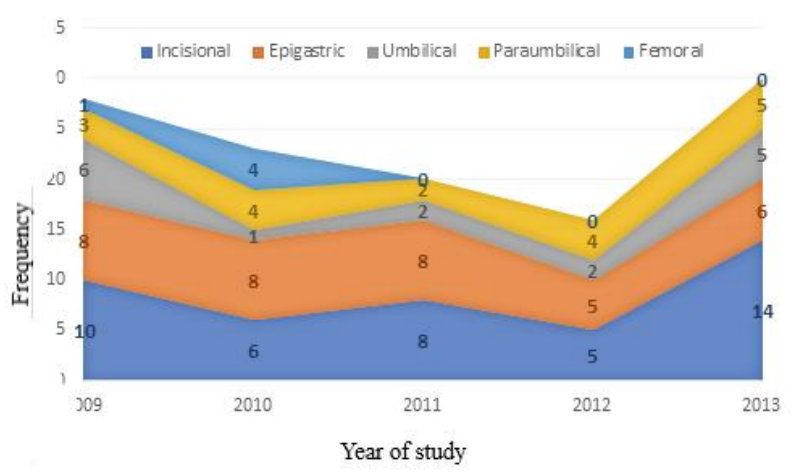

Fig. 3. Trend of ventral(non-groin) hernias in study population during study year.

TABLE III: TyPes OF ABDOMINAL WALl HERnias, RePAIR METHOD AND CHOICE OF ANESTHESIA

\begin{tabular}{|c|c|c|c|c|c|c|c|}
\hline \multirow[b]{2}{*}{ Type } & \multicolumn{3}{|c|}{ Repair method } & \multicolumn{4}{|c|}{ Anaesthesia } \\
\hline & Suture & Mesh & Laparoscopic & General & $\begin{array}{l}\text { Subarachnoid } \\
\text { block }\end{array}$ & Epidural & Field block \\
\hline Epigastric & 35 & 0 & 1 & 12 & 23 & 1 & 0 \\
\hline Paraumbilical & 17 & 1 & 0 & 5 & 12 & 0 & 1 \\
\hline Umbilical & 14 & 1 & 0 & 1 & 13 & 0 & 1 \\
\hline Incisional & 38 & 5 & 0 & 14 & 29 & 0 & 0 \\
\hline $\begin{array}{l}\text { Inguinal- } \\
\text { unilateral }\end{array}$ & 247 & 2 & 0 & 4 & 229 & 0 & 16 \\
\hline $\begin{array}{l}\text { Inguinal- } \\
\text { bilateral }\end{array}$ & 37 & 0 & 1 & 3 & 34 & 1 & 0 \\
\hline Femoral & 6 & 0 & 0 & 0 & 6 & 0 & 0 \\
\hline Total & 397 & 9 & 2 & 39 & 346 & 2 & 18 \\
\hline
\end{tabular}

TABLE IV: OPERATIVE TIME AND CADRE OF SURGEON PERFORMING HERNIAS

\begin{tabular}{|c|c|c|c|c|c|}
\hline Type of hernia & Snr Registrar & Consultant & Registrar & Total (\%) & $\begin{array}{c}\text { Operative } \\
\text { time(mean) }\end{array}$ \\
\hline $\begin{array}{l}\text { Inguinal - } \\
\text { unilateral }\end{array}$ & 37 & 160 & 50 & $\begin{array}{c}247 \\
(61.8)\end{array}$ & $72.8 \mathrm{mins}$ \\
\hline $\begin{array}{l}\text { Inguinal- } \\
\text { bilateral }\end{array}$ & 10 & 24 & 2 & $36(9.00)$ & $105.3 \mathrm{mins}$ \\
\hline Incisional & 31 & 11 & 1 & $43(10,8)$ & $103.0 \mathrm{mins}$ \\
\hline Epigastric & 15 & 16 & 2 & $33(8.3)$ & $55.8 \mathrm{mins}$ \\
\hline Paraumbilical & 6 & 10 & 2 & $18(4.5)$ & $58.5 \mathrm{mins}$ \\
\hline Umbilical & 1 & 10 & 2 & $13(3.2)$ & $61.9 \mathrm{mins}$ \\
\hline Femoral & 4 & 1 & 0 & $5(1.2)$ & 38.6 mins \\
\hline $\begin{array}{c}\text { Groin+ other } \\
\text { hernia }\end{array}$ & 1 & 4 & 0 & $5(1.2)$ & 77.6 mins \\
\hline Total & 105 & 236 & 59 & $400(100)$ & 71.7. mins \\
\hline
\end{tabular}

\section{DISCUSSION}

Symptomatic hernias should be repaired unless there are contra-indications to surgery or anaesthesia. Approximately half of the abdominal wall hernia repairs were performed in patients below the age of 40 years-208(52\%) with the peak age incidence in the 30-39 age group. Males were predominantly affected with a M:F ratio of 1.9:1. However, there was a higher distribution of ventral hernias in females. Inguinal hernia accounted for $287 / 405(70.9 \%)$ of anterior abdominal wall hernias. Documented reports of inguinal hernia from other parts of Nigeria are slightly higher at $78.2 \%$ in South-east, $76.9 \%-80.0 \%$ in North-west, and $84.8 \%$ in South- west regions [8]-[11]. This marginal difference is possibly due to inclusion of paediatric age group and emergent cases in those studies. Similarly, prevalence rates of $76.35 \%$ and $77.8 \%$ are reported for inguinal hernia from Pakistan and India, respectively but a lower rate of $56 \%$ is reported from Egypt-North Africa, with a higher distribution of umbilical/supraumbilical hernias from a high prevalence of liver disease and ascites [12], [13].

Aging predisposes to hernia occurrence. The observed age distribution with a noteworthy predominance of patients having abdominal wall hernia below 40 years and a peak in the fourth decade is not typical. This is possibly due to affordable cost of service in the study setting for this mostly out-of-pocket paying active age population. Also, the availability of hernia repair services in several private and other government-owned hospitals in the metropolitan setting of study may have contributed to skewing of data in a single centre. A male to female ratio of 7:1 was recorded for inguinal hernia but a female predominance for femoral hernia was noted in keeping with literature. A study on 
inguinal hernia from North west Nigeria reported an even higher M:F ratio of 16:1 [10]. In present study, ventral hernias were more common in females aged 30-39 years. From a well-kept hernia database in Europe (Denmark), umbilical hernia repairs in adults are predominantly performed in males aged 61-70 years, whereas epigastric hernia repairs are almost equally distributed by gender and mainly performed in patients aged 40-60 years [14].

All three types of anaesthesia (local, regional, and general) are suitable in most cases for abdominal wall hernia repair. The choice of anaesthesia is usually made by the surgeon before surgery. Regional anaesthesia by subarachnoid block was the most common anaesthetic technique in 345/405(85.2\%). Local anaesthesia often provides maximum comfort for patients when it is accurately performed in open repairs for groin hernias in some centres. However, inexperience with the local anaesthetic technique may cause discomfort to patients with an increased recurrence rate [15]. In contrast, the Danish hernia data base reports a much higher utilization of general anaesthesia for elective open inguinal hernia repair- $63.6 \%$ [16]. Laparoscopic ventral/inguinal hernia repair however generally requires general anaesthesia with endotracheal intubation. Trainee surgeons performed nearly threequarters of the hernia repairs while consultant surgeons performed majority of incisional hernia and paraumbilical hernia repairs.

Surgeons generally choose the most familiar technique or comply with the patients' preferences. The major repair options for hernias are by open tissue or mesh and minimally invasive repair techniques. Tissue approximation by open suture repair of anatomical defect was the most frequent repair method- 394/405(97.3\%). The total number of mesh repairs were limited but most frequent with incisional hernias $-5 / 43(11.6 \%)$. The choice of mesh to use in hernia repair depends on size of the defect, weakness of musculature, and surgeon preference. A reduction in the density of polypropylene to create light-weight mesh theoretically induces less foreign body response, improves abdominal wall compliance, causes less contraction or shrinkage of the mesh, and enables better tissue incorporation [17]. A good knowledge of groin anatomy and physiology by operating surgeon are pertinent to successful repair outcome.

A pilot case of laparoscopic trans abdominal preperitoneal repair (TAPP) was successfully recorded. In performing TAPP, a sound knowledge of a peculiar laparoscopic view, with myopectineal orifice, triangle of doom and ilio-pubic tract as important landmarks, is needed to prevent intra- and post-operative complications. Light -weight polypropylene mesh is associated with ease of introduction through the trocar and placement over myopectineal orifice. Fixation of the mesh was done using Protack ${ }^{\mathrm{TM}}$ fixation device with non-application of tacks below the ilio-pubic tract to avoid vascular injury or chronic post-operative pain. Transabdominal extraperitoneal inguinal hernia repair (TEP) is another laparoscopic technique for inguinal hernia repair. Composite meshes are preferred materials for laparoscopic ventral hernia repair to avoid the risk of visceral adhesion into the mesh [18]. However, in select cases, polypropylene mesh is acceptable if this can be completely excluded from bowel by interposition of omentum; however, a composite mesh should be considered as the current standard of care.

A limitation of this study is the retrospective design. An electronic record system is a worthwhile investment in the health budget for government-owned tertiary hospitals in Nigeria to facilitate the accurate compilation of local, regional, and national databases. Albeit the present study is an adequate baseline assessment to highlight the distribution of ventral hernias, resources needed in terms of theatre space, time spent on these procedures and the need for best practices including training in laparoscopic ventral/inguinal hernia repair. The development of a laparoscopy training curriculum requires essential equipment, trained team, and a reasonable case load to apply special skills initially learned from ex-vivo and in-vivo(porcine) models. The envisaged challenges of laparoscopic hernia repair in low-/middleincome countries majorly are availability of mesh fixation devices and added cost of this routine surgical procedures [19]. However, the gains of reduced post-post-operative pain, recurrence and shorter hospital stay are worthwhile benefits.

\section{CONCLUSION}

Suture repair is the predominant repair technique. Routine hernioplasty and laparoscopic hernia repair need to be encouraged.

\section{ACKNOWLEDGMENT}

We wish to thank Dr Stella C. Ibeneme for her assistance in collecting the data for this study.

\section{REFERENCES}

[1] M. Korenkov, A. Paul, S. Sauerland, E. Neugebauer, M. Arndt, J. P Chevrel, et al. "Classification and surgical treatment of incisional hernia. Results of an experts' meeting," Langenbecks Arch Surg, vol. 386, pp. 65-73, Feb 2001.

[2] H. Bougard, D. Coolen, R. de Beer, D. Folscher, J. C. Kloppers, M. Z. Koto, et al. "The Hernia Interest Group (HIG) of the South African Society of Endoscopic Surgeons (SASES)," South Afr J Surg, vol. 54, pp. S1-S32, Nov 2016.

[3] H. B. Devlin. "Trends in hernia surgery in the land of Astley Cooper," in Problems in general surgery, vol. 12, N. J. Soper, Ed, Philadelphia: Lippincott-Raven, 1995, pp. 85-92.

[4] N van Veenendaal, M Simon, W. Hope. "Consensus of international guidelines for management of groin hernias," Surg Endosc, vol. 34, pp. 2359-2377, Jun 2020.

[5] V. Consalvo, F. D' Auria, V. Salsano. "Chronic pain and Discomfort in primary uncomplicated Groin Hernia: A Prospective study comparing Transabdominal Pre-peritoneal repair (TAPP) to Open Repair Surgery with a 3-year follow-up," Surg Technol Int, vol. 36, pp. 119-123, May 2020.

[6] Y. W. Novitsky, D. R. Czerniach, K. W. Kercher, G. K. Kaban, K. A. Gallagher, J. J. Kelly, et al. "Advantages of laparoscopic transabdominal preperitoneal herniorrhaphy in the evaluation and management of inguinal hernias," Am J Surg, vol. 193, pp. 466-470, Apr 2007.

[7] M. C. Misra, V. K. Bansal, M. P. Kulkarni, D. K. Pawar. "Comparison of laparoscopic and open repair of incisional and primary ventral hernia: results of a prospective randomized study," Surg Endosc, vol. 20, pp. 1839-1845, Dec 2006.

[8] A. U. Ogbuanya, S. C. Emedike. "Elective repair of uncomplicated inguinal hernia in south eastern Nigerian," Asian J Med Sci, vol. 7, pp. 90-96, Nov 2016.

[9] N. Mbah. "Morbidity and mortality associated with inguinal hernia in North western Nigeria," West Afr J Med, vol. 26, pp. 288-292, Oct-Dec 2007. 
[10] E. S. Garba. "The pattern of adult external abdominal hernia in Zaria," Nig J Surg Res, vol. 2, pp. 12-15, 2000.

[11] O. O. Ayandipo, O. O. Afuwape, D. O. Irabor, A. I. Abdurrazzaaq. "Adult abdominal wall hernia in Ibadan," Ann Ibd. Pg. Med, vol. 13, pp. 94-99, Dec 2015.

[12] M. Sangwan, V. Sangwan, M. Garg, P. Mahendirutta, U. Garg. "Abdominal wall hernia in a rural population in India-Is spectrum changing?" Open Journal of Epidemiology, vol. 3, pp. 135-138, Aug 2013.

[13] S. A. Ammar, T. Ismail. "Abdominal Wall Hernias in Upper Egypt: A Different Spectrum," East Cent Afr J Surg, vol. 13, pp. 109-114, Aug/Sep 2008.

[14] J. Burcharth, M. S. Pedersen, H. C. Pommergaard, T. Bisgaard, C. B Pedersen, J. Rosenberg. "The prevalence of umbilical and epigastric hernia repair: a nationwide epidemiologic study," Hernia, vol. 19, pp. 815-819, Oct 2015.

[15] D. Prakash, L. Heskin, S. Doherty, R. Galvin. "Local anaesthesia versus spinal anaesthesia in inguinal hernia repair: a systematic review and meta-analysis," Surgeon, vol. 15, pp. 47-57, Feb 2017.

[16] H. Kehlet, M. Bay Nielsen. "Anaesthetic practice for groin hernia repair--a nation-wide study in Denmark 1998-2003," Acta Anaesthesiol Scand, vol. 49, pp. 143-146, Feb 2005.

[17] W. S. Cobb, K. W. Kercher, B. T. Heniford. "The argument for lightweight polypropylene mesh in hernia repair," Surg Innov, vol. 12, pp. 63-69, Mar 2005.

[18] H. Kulaçoğlu. "Current options in umbilical hernia repair in adult patients," Ulus Cerrahi Derg, vol. 31, pp. 157-161, Sep 2015.

[19] B. Nsadi, O. Detry, W. Arung. "Inguinal hernia surgery in developing countries: should laparoscopic repairs be performed?" Pan Afr Med J, vol. 27, pp. 1-3, May 2017. 